\title{
Medical Attitudes Survey for Female Dystrophinopathy Carriers in Japan
}

\author{
Michio Kobayashi ${ }^{1}$, Tomoyuki Hatakeyama ${ }^{1}$, Masatoshi Ishizaki ${ }^{2}$, Katsuhito Adachi ${ }^{3}$, \\ Mizuki Morita ${ }^{4}$, Naohiro Yonemoto ${ }^{5}$, Tsuyoshi Matsumura ${ }^{6}$, \\ Itaru Toyoshima ${ }^{1}$ and En Kimura ${ }^{7}$
}

\begin{abstract}
:
Objective This study attempted to clarify the current status of female dystrophinopathy carriers, including the numbers of patients, the status of genetic screening, the status of counseling, physicians' understanding, and barriers to registration.

Methods We sent out questionnaires to 402 physicians registered in the Remudy dystrophinopathy registry. The total number of responses received was 130 (response rate: $32 \%$ ).

Result In total, 1,212 cases of Duchenne muscular dystrophy, 365 cases of Becker muscular dystrophy, and 132 cases of female dystrophinopathy with a confirmed genetic mutation were encountered, and genetic testing was performed in the mother in 137, 23, and 12 cases, respectively. With respect to the risk of the onset of health problems, $25 \%$ of physicians always explained, $29 \%$ usually explained, $29 \%$ sometimes explained, and $13 \%$ never explained the risk to the mothers and female siblings of dystrophinopathy patients. The most common reason for not explaining the risk was a lack of knowledge/information. Thirty-five percent were familiar with the guidelines for testing the heart function of carriers.

Conclusion Fewer mothers of dystrophinopathy patients have undergone genetic testing in Japan than in other countries. A significant portion of doctors did not explain the risks of health problems due to a lack of knowledge. We hope this survey will lead to an increased discussion of female dystrophinopathy patients.
\end{abstract}

Key words: Duchenne muscular dystrophy, carrier, genetic diagnosis, health management, patient registry

(Intern Med 57: 2325-2332, 2018)

(DOI: 10.2169/internalmedicine.0163-17)

\section{Introduction}

Duchenne muscular dystrophy (DMD) and Becker muscular dystrophy (BMD) are X-linked muscular disorders caused by mutations in the dystrophin gene, with $60 \%$ of mothers of DMD patients and $90 \%$ of mothers of BMD patients being carriers of the genetic mutation (1). Skeletal muscle involvement (2), cardiomyopathy (3), psychiatric disorders (4), and deterioration of symptoms after pregnancy and delivery $(5,6)$ are known to occur in some carriers.
The life expectancy of DMD patients has improved during the last two decades $(7,8)$. The mean age at the time of death of DMD patients in Japan in 1999 was 23.6 years old, while it was 30.1 years old in 2012 (7). This disease forces an unexpected number of patients to live at home, which places an even greater burden on their caregivers. The health of the mother, often the main caregiver in Japan, influences the quality of life of the DMD patient; as such, managing the health of the mother is vital. It has been reported that the incidence of cardiomyopathy increases with age in female dystrophinopathy carriers (3), making it a more press-

${ }^{1}$ Department of Neurology, Akita National Hospital, Japan, ${ }^{2}$ Department of Neurology, Kumamoto Saishunso National Hospital, Japan, ${ }^{3}$ Department of Internal Medicine, Tokushima National Hospital, Japan, ${ }^{4}$ Department of Biorepository Research and Networking, Graduate School of Medicine, Dentistry and Pharmaceutical Sciences, Okayama University, Japan, ${ }^{5}$ Department of Biostatics, Kyoto University, Japan, ${ }^{6}$ Department of Neurology, Toneyama National Hospital, Japan and ${ }^{7}$ Translational Medical Center, National Center of Neurology and Psychiatry, Japan Received: September 1, 2017; Accepted: December 6, 2017; Advance Publication by J-STAGE: March 9, 2018 Correspondence to Dr. Michio Kobayashi, covayasi@hosp.go.jp 
ing problem as the mother ages. In previous reports, DNA testing was performed in $95 \%(210 / 222)$ of the mothers of DMD patients and $67 \%(42 / 63)$ of the mothers of BMD patients in the Netherlands $(9), 63 \%(645 / 1,021)$ of the firstdegree relatives of DMD patients in the UK (10), and $38 \%$ $(400 / 1,053)$ of the mothers of DMD patients in China (11). In a South Korean report, $19 \%(55 / 285)$ of patients who were screened for the dystrophin mutation were women (12). In a report of surveillance with an advocacy group mailing list and 50 Muscular Dystrophy Association clinics in the United States, $63 \%$ of the carriers of DMD/ BMD ( $n=833$ ) were aware of their cardiomyopathy risks (13). In contrast, little is known about the current status of health management for carriers of DMD/BMD in Japan.

We previously reported a questionnaire survey about carriers of DMD/BMD aimed at genetic counsellors in The Japan's National Liaison Council for Clinical Sections of Medical Genetics. In that report, we revealed that $61 \%$ of the counsellors informed carriers of the risk of cardiomyopathy and heart failure and advised carriers to undergo regular medical checkups (14); however, the current status of doctors informing and advising carriers is unclear.

The objectives of this study are as follows: 1) To determine the approximate number of Japanese female dystrophinopathy patients and the status of implementation of genetic screening; 2) to clarify the status of counseling for female family members of dystrophinopathy patients; 3) to assess physicians' understanding of female dystrophinopathy, and 4) to identify barriers to the registration of female dystrophinopathy patients.

\section{Materials and Methods}

\section{Subjects}

In August 2015, a questionnaire survey was mailed to 402 attending physicians of dystrophinopathy patients registered in Remudy, a Japanese national registry of patients with hereditary muscular disorders established in 2009 (15). As of the end of March 2017, 1,497 dystrophinopathy patients have been registered in the Remudy database (16).

Initially, the deadline for returning the survey questionnaire was the end of September 2015. We sent an e-mail reminder in October 2015, to let them know that the deadline had been extended to the end of October 2015.

\section{Questionnaire (Table 1)}

The physicians were asked to provide the following information: 1) the department in which they worked, 2) the number of dystrophinopathy patients they treated as the attending physician in 2014,3 ) the number of mothers of dystrophinopathy patients who underwent genetic testing, 4) if they explain to the mother and female siblings of dystrophinopathy patients that they may be carriers, 5) if they explain the health issues/risk of onset to the mothers and fe- male siblings of dystrophinopathy patients, 6) if they know about the Practical Guideline for Duchenne Muscular Dystrophy recommendations about carriers, 7) if they know that female dystrophinopathy has been designated an "intractable disease," 8) opinion about the registration of female dystrophinopathy patients, 9) severity they think is appropriate for the registration of female dystrophinopathy carriers, and 10) their opinion regarding the health management/registration of female dystrophinopathy patients/mutation carriers (open response).

Responses to the open question were analyzed with a qualitative content analysis, as reported elsewhere (17). Responses with similar meanings were grouped into subcategories. Similar subcategories were abstracted into main categories. These procedures were separately performed by two physicians who have specialized in neurology for over eight years, and disagreements were discussed to reach a consensus on appropriate categories.

\section{Statistical analyses}

The number of respondents was counted with each department and divided by the number of total respondents (Q1). The number of patients with dystrophinopathy, those with a confirmed genetic mutation, the mothers who had undergone genetic testing and the mothers with confirmed mutations were counted. The median, minimum, and maximum number of patients treated by a single physician were determined. The number of mothers of dystrophinopathy patients who underwent genetic testing was divided by the number of genetically confirmed dystrophinopathy patients to calculate the percentage of mothers who had been tested (Q2,3). The responses to the questions about counselling (Q4, 5) and knowledge $(\mathrm{Q} 6,7)$ were counted and divided by the number of all respondents. All data analyses was performed using the Microsoft Excel software program, ver. 2013 and 2016.

\section{Ethical approval}

The study protocol was approved by the local ethics committee of Akita National Hospital (Clinical Research Number 27-4).

\section{Results}

\section{Response rate}

The response rate was 32\% (130/402).

\section{Department of respondents (Q1)}

Seventy-two percent (93/130) were pediatricians, $27 \%$ (35/130) were neurologists, $1 \%$ (1/130) were orthopedists, and $1 \%(1 / 130)$ worked in the Department of Medical Genetics. 
Table 1. Questionnaire Items.

Q1. What department do you work in?

$\square$ Pediatrics $\quad \square$ Neurology $\quad \square$ Other ( $)$

Q2. How many patients did you treat as the attending physician from Jan. 1 to Dec. 31, 2014?

- Female dystrophinopathy : $\quad$ (Those with confirmed genetic mutation:

- Male DMD: $\quad$ (Those with confirmed genetic mutation:

- Male BMD: $\quad$ (Those with confirmed genetic mutation:

Q3. How many mothers of the patients reported in Q2 have undergone genetic testing to date?

- Mothers of female dystrophinopathy:

- Mothers of male DMD:

- Mothers of male BMD:

(Those with confirmed genetic mutation:

(Those with confirmed genetic mutation:

(Those with confirmed genetic mutation:

Q4. Do you explain to the mother and female siblings of dystrophinopathy patients that they may be carriers?
$\square$ 1. Always
$\square$ 2. Usually
$\square$ 3. Sometimes
4. Never

If the response is $2-4$, why did you not explain it to them (multiple responses allowed)?

$\square$ Possess limited knowledge/information about possibility of having genetic mutation

$\square$ Out of respect for psychological impact on mother $\quad \square$ Not enough time to explain

$\square$ Did not feel the need to explain

Q5. Do you explain health issues/risk of onset to the mothers and female siblings of dystrophinopathy patients?
$\square$ 1. Always
$\square$ 2. Usually
3. Sometimes
4. Never

If the response is 1-3, what things did you explain to them (multiple responses allowed)?
$\square$ Skeletal muscle symptoms $\square$ CNS manifestations
$\square$ Cardiomyopathy/heart failure
$\square$ Cardiomyopathy/heart failure during pregnancy/delivery
$\square$ Need for regular specialized tests incl. echocardiography

If the response is 2-4, why did you not explain it to them (multiple responses allowed)?

$\square$ Possess limited knowledge/information about health problems/risk of onset

$\square$ Out of respect for psychological impact on mother

$\square$ Not enough time to explain $\square$ Did not feel the need to explain

Q6. Do you know that the Practical Guideline for Duchenne Muscular Dystrophy (DMD) 2014 recommends that the cardiac function of carriers of the female dystrophin gene mutation should be evaluated once every approximately 5 years after reaching adulthood?
$\square$ 1. Yes
$\square$ 2. No

Q7. Did you know that muscular dystrophy was designated an intractable disease in Japan in July 2015, and that it is now possible to be certified for female dystrophinopathy if the diagnostic criteria and severity criteria are satisfied?

$\square$ Yes $\square$ No

Q8. What do you think about registration of female dystrophinopathy patients/mutation carriers?
$\square$ I'm for it.
$\square$ I'm not against it, but actual registration would be difficult
I'm against it.

Q9. What severity do think is appropriate for registration of female dystrophinopathy patients / carriers?
$\square$ Same as that for muscular dystrophy as a designated intractable disease*
$\square$ All those afflicted
$\square$ Asymptomatic carriers should also be included

Q10. Please give us your opinions regarding health management/registration of female dystrophinopathy patients/ carriers (open response).

\begin{abstract}
* Severity criteria for registration for muscular dystrophy as a designated intractable disease is to satisfy any one of the following criteria: Modified Rankin Scale $\geq 3$ (Requires some help, but can walk without assistance.), some help is required for meals/nutritional intake, respiratory symptoms hinder sleep, or shortness of breath occurs with activities of daily living such as getting dressed, NYHA $\geq$ II, ventricular tachycardia, atrial fibrillation, supraventricular tachyarrhythmia, second or third degree atrioventricular block, sick sinus syndrome, brain natriuretic peptide $>50 \mathrm{pg} / \mathrm{mL}$, and left ventricular ejection fraction $<55 \%$

DMD: Duchenne muscular dystrophy, BMD: Becker muscular dystrophy, CNS; Central nervous system,

Note; This table was written by translating the original Japanese questionnaire into English.
\end{abstract}

\section{Numbers of patients and status of genetic screening (Q2, 3) (Table 2)}

In total, 1,410 cases of $\mathrm{DMD}, 438$ cases of $\mathrm{BMD}$, and 172 cases of female dystrophinopathy were encountered, with a genetic mutation being confirmed in $86 \%(1,212 /$ $1,410), 83 \%$ (365/438), and $77 \%(132 / 172)$ of cases, respectively. The median (minimum-maximum) number of patients treated by a single physician was as follows: DMD [2 (0200)], BMD [1 (0-100)], and female dystrophinopathy [0 (0$30)$. Genetic testing was performed in the mother in $11 \%$ (137/1212), 6\% (23/365), and 9\% (12/132) of DMD, BMD, and female dystrophinopathy cases, respectively, and a genetic mutation was confirmed in 63\% (86/137), 78\% (18/ $23)$, and $50 \%(6 / 12)$ of cases, respectively.

\section{Counseling for female family members of dystro- phinopathy patients $(\mathbf{Q} 4,5)$ (Table 3)}

With respect to the possibility of the mother and female siblings of dystrophinopathy patients being carriers, $56 \%$ (73/130) of physicians always explained, 18\% (24/130) usually explained, 19\% (25/130) sometimes explained, and 4\% (5/130) never explained the possibility. The most common reason for not explaining it was "out of respect for the psy- 
Table 2. Number and Situation of Genetic Testing of Dystrophinopathy Patients and Their Mothers.

\begin{tabular}{|c|c|c|c|c|c|}
\hline Question & & total & pediatricians & neurologists & others \\
\hline \multirow[t]{11}{*}{ Q2. } & Number of all patients & & & & \\
\hline & Female dystrophinopathy & 172 & $37 \%(63 / 172)$ & $63 \%(109 / 172)$ & $0 \%(0 / 172)$ \\
\hline & Male BMD & 438 & $59 \%(259 / 438)$ & $41 \%(179 / 438)$ & $0 \%(0 / 438)$ \\
\hline & Number of genetically confirmed patien & & & & \\
\hline & Female dystrophinopathy & 132 & $32 \%(42 / 132)$ & $68 \%(90 / 132)$ & $0 \%(0 / 132)$ \\
\hline & Male DMD & 1,212 & $59 \%(716 / 1,212)$ & $41 \%(496 / 1,212)$ & $0 \%(0 / 1,212)$ \\
\hline & Male BMD & 365 & $63 \%(231 / 365)$ & $37 \%(134 / 365)$ & $0 \%(0 / 365)$ \\
\hline & Percentage of genetically confirmed pa & f genetically confirn & ed patients / numb & of all patients) & \\
\hline & Female dystrophinopathy & $77 \%(132 / 172)$ & $67 \%(42 / 63)$ & $83 \%(90 / 109)$ & $0 \%(0 / 0)$ \\
\hline & Male DMD & $86 \%(1,212 / 1,410)$ & $92 \%(716 / 782)$ & $80 \%(496 / 622)$ & $0 \%(0 / 6)$ \\
\hline & Male BMD & $683 \%(365 / 438)$ & $90 \%(231 / 259)$ & $75 \%(134 / 179)$ & $0 \%(0 / 0)$ \\
\hline \multirow[t]{13}{*}{ Q3. } & Number of mothers undergone genetic & & & & \\
\hline & Mothers of male DMD & 137 & $64 \%(87 / 137)$ & $36 \%(50 / 137)$ & $0 \%(0 / 137)$ \\
\hline & Mothers of male BMD & 23 & $39 \%(9 / 23)$ & $61 \%(14 / 23)$ & $0 \%(0 / 23)$ \\
\hline & Number of genetically confirmed mothe & & & & \\
\hline & Mothers of female dystrophinopathy & 6 & $50 \%(3 / 6)$ & $50 \%(3 / 6)$ & $0 \%(0 / 6)$ \\
\hline & Mothers of male DMD & 86 & $59 \%(51 / 86)$ & $41 \%(35 / 86)$ & $0 \%(0 / 86)$ \\
\hline & Mothers of male BMD & 18 & $33 \%(6 / 18)$ & $66 \%(12 / 18)$ & $0 \%(0 / 18)$ \\
\hline & Percentage of genetically tested mother & ted mother / number & f genetically confi & ned child patients & ported in $Q 2$ ) \\
\hline & Mothers of female dystrophinopathy & $9 \%(12 / 132)$ & $14 \%(6 / 42)$ & $7 \%(6 / 90)$ & $0 \%(0 / 0)$ \\
\hline & Mothers of male DMD & $11 \%(137 / 1,212)$ & $12 \%(87 / 716)$ & $10 \%(50 / 496)$ & $0 \%(0 / 0)$ \\
\hline & Mothers of male BMD & $6 \%(23 / 365)$ & $4 \%(9 / 231)$ & $10 \%(14 / 134)$ & $0 \%(0 / 0)$ \\
\hline & Percentage of genetically confirmed mo & of genetically confirn & ed mothers / numb & of tested mother) & \\
\hline & Mothers of female dystrophinopathy & $50 \%(6 / 12)$ & $50 \%(3 / 6)$ & $50 \%(3 / 6)$ & $0 \%(0 / 0)$ \\
\hline
\end{tabular}

DMD: Duchenne muscular dystrophy, BMD: Becker muscular dystrophy

chological impact." With respect to the risk of the onset of health problems, $25 \%(33 / 130)$ of physicians always explained, $28 \%$ (37/130) usually explained, 29\% (38/130) sometimes explained, and $13 \%$ (17/130) never explained the risk. The most common reason for not explaining it was a "lack of knowledge/information (24\%, 31/130)."

Among the 130 respondents, 64\% (83/130) of attending physicians explained about musculoskeletal symptoms, 56\% (73/130) explained about cardiomyopathy and heart failure, $28 \%(36 / 130)$ explained the need for regular specialized tests, including echocardiography, 19\% (25/130) explained about cardiomyopathy/heart failure during pregnancy/delivery, $18 \%$ (24/130) explained about the need for medical checkups, and $8 \%$ (11/130) explained about central nervous system symptoms.

\section{Knowledge of female dystrophinopathy $($ Q6, 7) (Ta-} ble 3)

Thirty-five percent (45/130) were familiar with the guidelines on testing the heart function of female carriers, and $42 \%$ (54/130) knew that dystrophinopathy was now designated as an "intractable disease," with the associated medical expenses covered by the national government and prefectures in Japan.

\section{Thoughts on registration $(Q 8,9)$}

Seventy-three percent agreed with registration (more results are available in the Supplementary material).

\section{Content analyses of the responses to the open question (Q10) (Table 4)}

Forty-eight physicians responded to the open question, and a total of 58 opinions were received. Regarding the results of the content analysis, 66\% (38/58) of the responses were categorized as a "matter requiring improvement," and $24 \%(14 / 58)$ were categorized as having "a positive attitude toward this study." The subcategories of "matter requiring improvement" included "Delicate problem," "Genetic counseling-related problem," "Financial problem," "Lack of information," "Problem of young carriers," "Problem of asymptomatic persons," "Support for the mother," "Unclear advantages of registration," "Social system," and "Problem of genetic testing." The subcategories of "a positive attitude toward this study" included "It was enlightening," "Important problem," and "Positive attitude toward registration". 
Table 3. Difference of Answers with Pediatricians, Adult Neurologists, and Others.

\begin{tabular}{|c|c|c|c|c|c|}
\hline Question & & $\begin{array}{c}\text { total } \\
(n=130)\end{array}$ & $\begin{array}{l}\text { pediatricians } \\
\quad(\mathrm{n}=93)\end{array}$ & $\begin{array}{l}\text { neurologists } \\
\qquad(\mathrm{n}=35)\end{array}$ & $\begin{array}{l}\text { others } \\
(n=2)\end{array}$ \\
\hline \multirow[t]{11}{*}{ Q4. } & \multicolumn{5}{|c|}{ Explanation to the mother and female siblings of dystrophinopathy patients that they may be carriers. } \\
\hline & Always & $56 \%(73 / 130)$ & $65 \%(60 / 93)$ & $34 \%(12 / 35)$ & $50 \%(1 / 2)$ \\
\hline & Usually & $18 \%(24 / 130)$ & $18 \%(17 / 93)$ & $20 \%(7 / 35)$ & $0 \%(0 / 2)$ \\
\hline & Sometimes & $19 \%(25 / 130)$ & $13 \%(12 / 93)$ & $37 \%(13 / 35)$ & $0 \%(0 / 2)$ \\
\hline & Never & $4 \%(5 / 130)$ & $2 \%(2 / 93)$ & $6 \%(2 / 35)$ & $50 \%(1 / 2)$ \\
\hline & Not answered & $2 \%(3 / 130)$ & $2 \%(2 / 93)$ & $3 \%(1 / 35)$ & $0 \%(0 / 2)$ \\
\hline & \multicolumn{5}{|c|}{ Reason of not explained (multiple responses allowed) } \\
\hline & Out of respect for psychological impact & $22 \%(28 / 130)$ & $18 \%(17 / 93)$ & $31 \%(11 / 35)$ & $50 \%(1 / 2)$ \\
\hline & Lack of knowledge / information & $9 \%(12 / 130)$ & $8 \%(7 / 93)$ & $11 \%(4 / 35)$ & $0 \%(0 / 2)$ \\
\hline & Not enough time to explain & $5 \%(6 / 130)$ & $3 \%(3 / 93)$ & $9 \%(3 / 35)$ & $0 \%(0 / 2)$ \\
\hline & Did not feel the need to explain & $4 \%(5 / 130)$ & $2 \%(2 / 93)$ & $9 \%(3 / 35)$ & $0 \%(0 / 2)$ \\
\hline \multirow[t]{18}{*}{ Q5. } & \multicolumn{5}{|c|}{ Explanation to the mothers and female siblings of dystrophinopathy patients about health issues/risk of onset } \\
\hline & Always & $25 \%(33 / 130)$ & $28 \%(26 / 93)$ & $26 \%(6 / 35)$ & $50 \%(1 / 2)$ \\
\hline & Usually & $29 \%(37 / 130)$ & $28 \%(26 / 93)$ & $31 \%(11 / 35)$ & $0 \%(0 / 2)$ \\
\hline & Sometimes & $29 \%(38 / 130)$ & $25 \%(23 / 93)$ & $43 \%(15 / 35)$ & $0 \%(0 / 2)$ \\
\hline & Never & $13 \%(17 / 130)$ & $15 \%(14 / 93)$ & $6 \%(2 / 35)$ & $50 \%(1 / 2)$ \\
\hline & Not answered & $4 \%(5 / 130)$ & $4 \%(4 / 93)$ & $3 \%(1 / 35)$ & $0 \%(0 / 2)$ \\
\hline & \multicolumn{5}{|c|}{ Reason of not explained (multiple responses allowed) } \\
\hline & Out of respect for psychological impact & $19 \%(25 / 130)$ & $18 \%(17 / 93)$ & $20 \%(7 / 35)$ & $0 \%(0 / 2)$ \\
\hline & Lack of knowledge / information & $24 \%(31 / 130)$ & $25 \%(23 / 93)$ & $23 \%(8 / 35)$ & $50 \%(1 / 2)$ \\
\hline & Not enough time to explain & $7 \%(9 / 130)$ & $5 \%(5 / 93)$ & $11 \%(4 / 35)$ & $0 \%(0 / 2)$ \\
\hline & Did not feel the need to explain & $8 \%(11 / 130)$ & $8 \%(7 / 93)$ & $11 \%(4 / 35)$ & $0 \%(0 / 2)$ \\
\hline & \multicolumn{5}{|c|}{ Contents of explanation (multiple responses allowed) } \\
\hline & Musculoskeletal disorders & $64 \%(83 / 130)$ & $62 \%(58 / 93)$ & $69 \%(24 / 35)$ & $50 \%(1 / 2)$ \\
\hline & Cardiomyopathy / heart failure & $56 \%(73 / 130)$ & $53 \%(49 / 93)$ & $66 \%(24 / 35)$ & $50 \%(1 / 2)$ \\
\hline & Need for echocardiography & $28 \%(36 / 130)$ & $24 \%(22 / 93)$ & $40 \%(14 / 35)$ & $0 \%(0 / 2)$ \\
\hline & Cardiomyopathy during pregnancy/delivery & $19 \%(25 / 130)$ & $19 \%(18 / 93)$ & $20 \%(7 / 35)$ & $0 \%(0 / 2)$ \\
\hline & Need for medical check-ups & $18 \%(24 / 130)$ & $16 \%(15 / 93)$ & $26 \%(9 / 35)$ & $0 \%(0 / 2)$ \\
\hline & CNS manifestations & $8 \%(11 / 130)$ & $10 \%(9 / 93)$ & $6 \%(2 / 35)$ & $0 \%(0 / 2)$ \\
\hline Q6. & Knowing with guidelines & $35 \%(45 / 130)$ & $29 \%(27 / 93)$ & $49 \%(17 / 35)$ & $50 \%(1 / 2)$ \\
\hline Q7. & Knowing with designated intractable disease & $42 \%(54 / 130)$ & $33 \%(31 / 93)$ & $66 \%(23 / 35)$ & $0 \%(0 / 2)$ \\
\hline
\end{tabular}

Note; The rate of selecting each option included in each question item (number of selected respondents / number of all respondents) of total, pediatricians, adult neurologist, and others are shown. CNS: Central nervous system

\section{Differences in responses between pediatricians and neurologists (Table 2, 3)}

More female dystrophinopathy patients were treated by neurologists $(63 \%, 109 / 172)$ than pediatricians $(37 \%, 63 /$ 172) (Q2). More pediatricians $(65 \%, 60 / 93)$ than neurologists $(34 \%, 12 / 35)$ always explained to female family members of dystrophinopathy patients that they might be carriers (Q4). More neurologists than pediatricians knew about the guideline [49\% (17/35) of neurologists, 29\% (27/93) of pediatricians].

\section{Discussion}

Our study revealed that there were at least 130 genetically confirmed female dystrophinopathy carriers in Japan. There seemed to be fewer mothers who underwent genetic screening in our study (6-11\%) than in previous reports from the Netherlands $(67-95 \%)$ and the UK $(63 \%)(9,10)$. As mentioned above, fewer females seem to undergo genetic screen- ing in Asian countries than in Europe $(11,12)$. Genetic testing and counseling of carriers are provided as a medical service under the health insurance system in the Netherlands and the UK, but not in Japan, Korea, or China, which may be one reason why genetic testing is performed more often in Europe than in Asian countries. In a recent report on the US DuchenneConnect patient registry, the cost of testing was the most commonly identified barrier to genetic screening (18). In addition, we considered two other possible reasons for why fewer mothers undergo genetic examinations in Japan: insufficient explanation of the risk of the onset from clinicians, and a conservative attitude toward genetic testing in general in Japan.

In terms of counseling for female family members, it appears the majority of Japanese doctors decide to explain or not to explain the risk on a case-by-case basis on consideration of the psychological impact. In contrast, doctors in the Netherlands seem to have a more positive attitude toward counseling, with index patients being asked to distribute "family letters" that provide information about the disease, 
Table 4. Results of Analysis of Responses to Open Question.

\begin{tabular}{|c|c|c|c|}
\hline Category & Subcategory & & Examples of the opinions \\
\hline \multirow[t]{10}{*}{$\begin{array}{l}\text { Matters requiring } \\
\text { improvement } \\
(66 \%, 38 / 58)\end{array}$} & Delicate problem & $(10 \%, 6 / 58)$ & $\begin{array}{l}\text { Being diagnosed as a carrier leaves no doubt that the disorder was } \\
\text { passed down from the mother, giving rise to situations where it is } \\
\text { very difficult to explain it to some families. }\end{array}$ \\
\hline & Genetic counseling-related problem & $(9 \%, 5 / 58)$ & It would be difficult at institutions with no genetics specialists. \\
\hline & Financial problem & $(9 \%, 5 / 58)$ & Where will you get the funds for sequencing? \\
\hline & Lack of information & $(9 \%, 5 / 58)$ & $\begin{array}{l}\text { There is still much that is unknown, so I don't know how much I } \\
\text { should try to explain. I'd like to have an evidence-based guideline. }\end{array}$ \\
\hline & Problem of young carriers & $(5 \%, 3 / 58)$ & I don't know what I should do with the patient who are minors. \\
\hline & Problem of asymptomatic persons & $(3 \%, 2 / 58)$ & $\begin{array}{l}\text { It should target people who have a subjective symptom and who } \\
\text { consult a doctor of their own volition. }\end{array}$ \\
\hline & Support for the mother & $(3 \%, 2 / 58)$ & I hope that society becomes more supportive of the mother. \\
\hline & Advantages of registration are unclear & $(3 \%, 2 / 58)$ & $\begin{array}{l}\text { You should clarify the advantages of registration and whether the } \\
\text { concerns of people diagnosed as carriers can be addressed. }\end{array}$ \\
\hline & Problem of genetic testing & $(2 \%, 1 / 58)$ & Even male patients rarely undergo genetic testing. \\
\hline & Other problems of registration & $(5 \%, 3 / 58)$ & $\begin{array}{l}\text { Will people with Turner syndrome with coexisting } \\
\text { dystrophinopathy be able to register? I feel like it would be unfair } \\
\text { if they could not register and did not get all the information they } \\
\text { need. }\end{array}$ \\
\hline \multirow{3}{*}{$\begin{array}{l}\text { Positive attitude } \\
\text { toward study } \\
(24 \%, 14 / 58)\end{array}$} & It was enlightening & $(12 \%, 7 / 58)$ & I have little knowledge, so I need to study. \\
\hline & Important problem & $(7 \%, 4 / 58)$ & I think it is an important problem. \\
\hline & Positive attitude toward registration & $(3 \%, 2 / 58)$ & $\begin{array}{l}\text { I think that registration would be beneficial as patients may } \\
\text { become candidates for read through and exon skipping treatment. }\end{array}$ \\
\hline \multirow[t]{2}{*}{$\begin{array}{l}\text { Others } \\
(10 \%, 6 / 58)\end{array}$} & I am actually treating carriers & $(7 \%, 4 / 58)$ & $\begin{array}{l}\text { I'm currently administering beta-blocker and ACE inhibitor to } \\
\text { three patients with female dystrophinopathy. }\end{array}$ \\
\hline & Present status of genetic counseling & $(3 \%, 2 / 58)$ & Genetic counseling is required at our institution. \\
\hline
\end{tabular}

Note; This table was written by translating the analysis result in Japanese into English.

inheritance, health risks, possible treatment options, and screening to their first-degree relatives or the children of those relatives (19). In a recent report of a survey of perspectives on carrier testing and communication within the family, the importance of autonomy is emphasized (20), which seems to differ from the traditional paternalism in old medical and social systems in Japan (21).

Our study showed that the most common reason for not explaining the risk in Japan is a lack of knowledge and information. Regarding female dystrophinopathy, many attending physicians were not familiar with the guideline or the fact that it had been newly designated an "intractable disease" under Japanese law in 2015. The knowledge of attending physicians seemed to be insufficient to explain female dystrophinopathy adequately. We therefore feel that carrying out this survey was worthwhile, as physicians became much more familiar with female dystrophinopathy through it.

However, regardless of the reasoning, we must not forget that a delay in the diagnosis and insufficient explanation may lead to a delay in treatment. We hope that barriers, such as the cost of a diagnosis, psychosocial problems, and lack of knowledge of the doctors, will be overcome.

In the future, more female dystrophy patients will be openly registered in Remudy in order to collect adequate information and estimate the prevalence of female dystrophinopathy, the incidence of symptoms, and the prognoses here in Japan. However, the results of our content analysis revealed that many physicians had noted various issues with adding female dystrophinopathy patients to a registry, even if they agree to this addition, including "Delicate problems," "Genetic counseling-related problems," "Financial problems," and "Lack of information." Therefore, we need to proceed carefully.

Several limitations associated with the present study warrant mention. First, questionnaires were only mailed to registered physicians as an anonymous survey to protect each patient's personal information. The response rate was lower than initially expected, possibly due to the low interest of some physicians in female dystrophinopathy. Second, some patients with cardiomyopathy without skeletal muscle symptoms may not have been diagnosed and not included in this study. Third, there is some bias in this study since we have incompletely covered the population of dystrophinopathy patients in Japan. As the total number of dystrophinopathy patients is unknown in Japan, we cannot show what percentage of dystrophinopathy patients were included in this survey. Furthermore, the patients in this study included those who did not want to be registered in Remudy, even if their disease was genetically proven. As such, we cannot compare the numbers of patients in this study with those registered in Remudy. The numbers of patients were not precise for the following reasons: 1) We asked for the approximate number 
of patients, 2) we did not define the criteria of female dystrophinopathy, and 3) as this was an anonymous survey, we were unable to omit overlapping cases coincidentally reported from different hospitals. Fourth, the responding physicians may have been more interested in the carrier problem than those who did not respond; therefore, the results may be biased toward being more likely to explain the risks and being more familiar with the guideline. Finally, regarding the open question, it may have been difficult to respond with a negative opinion. For female dystrophinopathy, medical and social attitudes may vary from country to country, so it is important for us to recognize the circumstances and related problems of each country with extensive insight.

\section{Conclusion}

In conclusion, we revealed some problems concerning female dystrophinopathy, such as the lower rate of mothers of DMD/BMD patients having undergone genetic testing in Japan than in other countries, and a significant portion of doctors lacked information and did not explain the risks of onset of health problems to the female family members of DMD/BMD patients. We hope that our survey will lead to increased discussion of female dystrophinopathy patients and that more evidence related to female dystrophinopathy will be gathered in the future using the registration system.

These findings were reported at the 57th Annual Meeting of the Japanese Society of Neurology and 15th Annual Scientific Meeting of Asian Oceanian Myology Center (AOMC).

The authors state that they have no Conflict of Interest (COI).

\section{Financial Support}

This work was supported in part by an Intramural Research Grant for Neurological and Psychiatric Disorders of the NCNP (26-7).

\section{Acknowledgement}

We thank the attending physicians who responded to the questionnaire. We also thank Dr. Komaki and Dr. Mori for their useful comments during the creation of the questionnaire; Ms. Kusunoki, Ms. Munakata, and Ms. Koori for the design and sending of the questionnaire; and Ms. Watanabe for administrative support. We express our appreciation and condolences for the late Dr. Mitsuru Kawai, former director of National Hospital Organization Higashisaitama Hospital, who was a founder and godfather of Remudy.

\section{References}

1. Lee T, Takeshima Y, Kusunoki N, et al. Differences in carrier frequency between mothers of Duchenne and Becker muscular dystrophy patients. J Hum Genet 59: 46-50, 2014.

2. Hoogerwaard EM, Bakker E, Ippel PF, et al. Signs and symptoms of Duchenne muscular dystrophy and Becker muscular dystrophy among carriers in The Netherlands: a cohort study. Lancet 353: 2116-2119, 1999.

3. Politano L, Nigro V, Nigro G, et al. Development of cardiomyopa- thy in female carriers of Duchenne and Becker muscular dystrophies. JAMA 275: 1335-1338, 1996.

4. Imbornoni L, Price ET, Andrews J, Meaney FJ, Ciafaloni E, Cunniff C. Diagnostic and clinical characteristics of earlymanifesting females with Duchenne or Becker muscular dystrophy. Am J Med Genet A 164a: 2769-2774, 2014.

5. Hori H, Maeda Y, Ishizaki M, et al. A carrier with de novo Mutation in the dystrophin gene whose myopathic symptoms became seriously progressive after pregnancy and delivery. Muscle Nerve 52: 913-914, 2015.

6. Soltanzadeh P, Friez MJ, Dunn D, et al. Clinical and genetic characterization of manifesting carriers of DMD mutations. Neuromuscul Disord 20: 499-504, 2010.

7. Saito T, Tatara K, Kawai M. Changes in clinical condition and causes of death of inpatients with Duchenne muscular dystrophy in Japan from 1999 to 2012. Rinsho Shinkeigaku 54: 783-790, 2014 (in Japanese, Abstract in English).

8. Passamano L, Taglia A, Palladino A, et al. Improvement of survival in Duchenne Muscular Dystrophy: retrospective analysis of 835 patients. Acta Myol 31: 121-125, 2012.

9. Helderman-van den Enden AT, van den Bergen JC, Breuning MH, et al. Duchenne/Becker muscular dystrophy in the family: have potential carriers been tested at a molecular level? Clin Genet 79: 236-242, 2011.

10. McGowan R, Challoner BR, Ross S, et al. Results of Duchenne muscular dystrophy family screening in practice: leaks rather than cascades? Clin Genet 83: 187-190, 2013.

11. Yang J, Li SY, Li YQ, et al. MLPA-based genotype-phenotype analysis in 1053 Chinese patients with DMD/BMD. BMC Med Genet 14: 29, 2013.

12. Lee SH, Lee JH, Lee KA, Choi YC. Clinical and Genetic Characterization of Female Dystrophinopathy. J Clin Neurol 11: 248-251, 2015.

13. Bobo JK, Kenneson A, Kolor K, Brown MA. Adherence to american academy of pediatrics recommendations for cardiac care among female carriers of Duchenne and Becker muscular dystrophy. Pediatrics 123: e471-e475, 2009.

14. Kobayashi M, Ishizaki M, Adachi K, et al. Survey on genetic counseling and health management for symptomatic and asymptomatic female dystrophinopathy carriers in Japan today. Rinsho Shinkeigaku 56: 407-412, 2016 (in Japanese, Abstract in English).

15. Nakamura H, Kimura E, Mori-Yoshimura M, et al. Characteristics of Japanese Duchenne and Becker muscular dystrophy patients in a novel Japanese national registry of muscular dystrophy (Remudy). Orphanet J Rare Dis 8: 60, 2013.

16. Okubo M, Goto K, Komaki H, et al. Comprehensive analysis for genetic diagnosis of Dystrophinopathies in Japan. Orphanet J Rare Dis 12: 149, 2017.

17. Aho AC, Hultsjo S, Hjelm K. Health perceptions of young adults living with recessive limb-girdle muscular dystrophy. J Adv Nurs 72: 1915-1925, 2016.

18. Bogue L, Peay H, Martin A, Lucas A, Ramchandren S. Knowledge of carrier status and barriers to testing among mothers of sons with Duchenne or Becker muscular dystrophy. Neuromuscul Disord 26: 860-864, 2016.

19. van der Roest WP, Pennings JM, Bakker M, van den Berg MP, van Tintelen JP. Family letters are an effective way to inform relatives about inherited cardiac disease. Am J Med Genet A 149a: 357-363, 2009.

20. Hayes B, Hassed S, Chaloner JL, Aston CE, Guy C. Duchenne muscular dystrophy: a survey of perspectives on carrier testing and communication within the family. J Genet Couns 25: 443-453, 2016.

21. Ito M, Tanida N, Turale S. Perceptions of Japanese patients and their family about medical treatment decisions. Nurs Health Sci 12: 314-321, 2010. 
The Internal Medicine is an Open Access article distributed under the Creative Commons Attribution-NonCommercial-NoDerivatives 4.0 International License. To view the details of this license, please visit (https://creativecommons.org/licenses/ by-nc-nd/4.0/).

(C) 2018 The Japanese Society of Internal Medicine

Intern Med 57: 2325-2332, 2018 